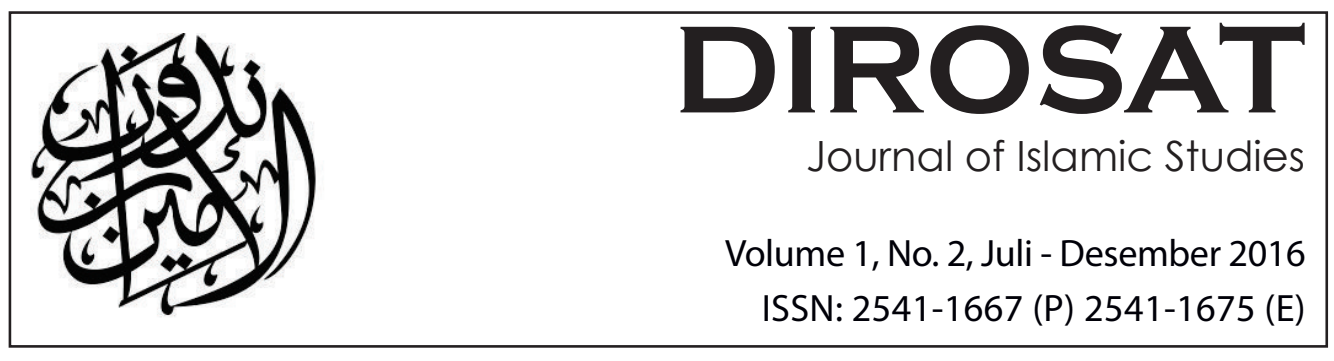

\title{
KURIKULUM TAUHID \\ DI UNIVERSITAS ISLAM \\ (Refleksi Terhadap Insan Kamil di Bidang Pendidikan)
}

\section{Asmu'i}

Praktisi Pendidikan Samarinda, Kalimantan.

Abstrak: Sebagai medium terpenting pengembangan peradaban, universitas Islam harus mampu merefleksikan sosok manusia yang mencerminkan sifat-sifat Tuhan. Manusia adalah pusat dari peradaban. Sosok manusia yang mampu membangun peradaban adalah manusia yang beradab, yaitu sosok yang merefleksikan sifat-sifat Tuhan tadi. Manusia seperti inilah yang disebut insan kamil. Secara mendasar, struktur dan kurikulum universitas Islam harus diambil dari hakikat manusia yang bersifat utuh, yakni yang berdimensi permanen dan spiritual, serta material dan emosional sekaligus. Kemudian pada tataran praktisnya, aktifitas penelitian dalam kegiatan pendidikan melibatkan berbagai metode, seperti religius dan ilmiah, empiris dan rasional, deduktif dan induktif, subjektif dan objektif, tanpa menjadikan salah satu metode lebih dominan dari yang lain. Karena kurikulum universitas ini berbasis dan melibatkan segenap potensi 'manusia beradab' dalam satu kesatuan organ yang utuh dan holistik, maka disebut kurikulum tauhidi. 
Singkatnya, universitas Islam adalah refleksi dari insan kamil ataupun universal (al-insān al-kullīatau al-insān al-kāmil), yang diarahkan untuk membentuk sosok manusia sempurna dan seutuhnya.

Kata Kunci: Insan Kamil, Universitas Islam, Kurikulum Tauhidi, Adab/Ta'dīb

\begin{abstract}
As the most important medium of developing civilization, Islamic University should be able to reflect on human figure which reflects the nature of God. The human being is the center of civilization. Human figure who could build the civilized human civilization is the figure who reflects the nature of God. This man is known by term insan kamil. Fundamentally, the structure and curriculum of Islamic University should be taken from the nature of man which consists permanent and spiritual dimension as well as material and emotional dimension. Then in practical level, research activities in the educational activities should involve various methods, such as religious and scientific, empirical and rational, deductive and inductive, subjective and objective, without making one method is more dominant than the other. Because of the University's curriculum-based involve all 'civilized human beings' potential in a whole organ intact and holistic, then it is called tauhidi curriculum. In short, the Islamic University is a reflection of the insan kamil or universal human being (al-insān al-kullīor al-insān al-kämil), which is directed to form a human figure perfectly and completely.
\end{abstract}

Keywords: Insan Kamil, Islamic university, tauhidi curriculum, Adab/Ta'dīb

\title{
A. Pendahuluan
}

alah satu dampak hegemoni Barat hari ini adalah lahirnya sikap mental inferior di sebagian masyarakat Muslim dengan meniru begitu saja pola dan model universitas yang khas Barat. Kelompok ini pada umumnya menganggap ilmu itu netral, ${ }^{1}$ sehingga tidak masalah mengambil ilmu apapun

1 Menurut Wan Daud, Al-Attas adalah ilmuwan Muslim pertama yang menegaskan bahwa ilmu itu tidak netral. Baca Wan Daud, Rihlah Ilmiah Wan Mohd Nor Wan Daud: Dari Neomodernisme ke Islamisasi Ilmu Pengetahuan Kontemporer, (Malaysia-Indonesia: UTM-CASIS \& INSISTS, 2012), 343-344. Lihat juga karya Al-Attas tentang ini: Islam and Secularism, (Kuala Lumpur: ISTAC, 1993), 133-134; Risalah Untuk Kaum Muslimin, (Kuala Lumpur: ISTAC, 2001), 61-63. Sebagaimana Al-Attas, Nursi juga menyiratkan pandangan senada. Lihat Bediuzzaman Said Nursi, Al-Maktūbāt, terj. Ihsan Kasim Salih, (Al-Qahirah: Syirkah Sozler li an-Nasyr, 2004), 28 \& 569-570; Al-Lama'āt, terj. Ihsan Kasim Salih, (Al-Qahirah: Syirkah Sozler li an-Nasyr, 2004), p. 176-177; Anwār al-Haqüqah: 
dari Barat asal membawa "kemajuan". Sebab bagi mereka, Barat merupakan simbol kemajuan dalam ilmu pengetahuan, kecanggihan metodologi penelitian dan pengkajian. ${ }^{2}$ Tipikal kelompok Muslim inilah yang disebut sebagai kelompok modernis dan sekuleris oleh Cheryl Bernard. ${ }^{3}$

Akibatnya, kurikulum pendidikan Islam yang awalnya bersifat tauhidi menjadi dikotomis; ${ }^{4}$ memisahkan antara yang material dari yang spiritual, memisahkan subjek dari objek secara radikal, antara ilmu umum dan ilmu agama, yang empiris dari rasional, melepaskan fisika dari metafisika, dan seterusnya. Bahkan dalam perkembangan selanjutnya, universitas banyak menawarkan ilmu-ilmu praktis, dan tujuan pendidikan pun hanya berorientasi mencari kerja; keuntungan duniawi semata. Sehingga kebanyakan mahasiswanya dan masyarakat secara luas juga berorientasi pada dunia kerja semata. Mahasiswa menjadi kehilangan idealismenya.

Makanya tidak heran jika universitas Islam malah melahirkan sarjana dan ilmuwan yang split (terbelah); ada kubu yang hanya mengakui sumber-sumber empiris dan rasional sebagai jalan mendapat ilmu, dan kubu lainnya lebih memberi penekanan pada ilmu-ilmu yang berdasarkan pada khabar. Padahal semua sumber ilmu tersebut masuk dalam epistemologi Islam, sekaligus dalam aqidah Islam. Dengan demikian, westernisasi dalam bidang pendidikan telah menyebabkan pendidikan Islam kehilangan perannya dalam mengaitkan ilmu pengetahuan dengan pandangan hidup Islam (Islamic Worldview).

Seharusnya universitas Islam mampu mencetak sarjana-sarjana yang menguasai berbagai bidang ilmu keislaman sekaligus dan berperan dalam berbagai sektor kehidupan umat. Sebab figur riil universitas Islam adalah Nabi Muhammad saw sebagai insan kamil. Tapi sayangnya, ilmu-ilmu yang

Mabāhith fì al-Tașawwuf wa al-Sulūk, terj. Ihsan Kasim Salih, (Al-Qahirah: Syirkah Sozler li anNasyr, 20o6), 56 .

2 Hamid Fahmi Zarkasyi, "Memahami Barat", dalamJurnal Pemikiran dan Peradaban Islam:ISLAMIA, Vol. III, No. 2, Januari-Maret, (Jakarta Selatan: Khairul Bayan, 2007), 6.

3 Bagi Barat, mereka adalah Muslim yang justru membantu Barat. Baca lebih jauh karya-karya Cheryl Bernard: Civil Democratic Islam, Partners, Resources and Strategies (2003); U.S. Strategy in the Muslim World After 9/11 (2004); The Muslim World After 9/11 (2004); dan Three Years After: Next Steps in the War on Terror (2005).

4 Baca lebih jauh tentang dualisme dalam Hamid Fahmy Zarkasyi, Misykat:Refleksi tentang Islam, Westernisasi \& Liberalisasi, (Jakarta: INSISTS, 2012), 103-107. 
dikuasai tidak lagi terkait secara konseptual dengan konsep-konsep Islam. dan universitas menjadi kehilangan perannya melahirkan pemimpin bangsa dan umat secara luas, untuk membangun kembali peradaban Islam.

Jika dulu di pintu gerbang Universitas Granada tertulis slogan "Dunia hanya terdiri dari empat unsur: pengetahuan orang bijak, keadilan penguasa, doa orang shalih dan keberanian kestaria", masalahnya apakah saat ini universitas Islam mampu menghasilkan orang alim, shalih, adil dan mujahid? Untuk itu, tulisan ini bermaksud mendiskusikan bagaimana seharusnya kurikulum pendidikan universitas Islam harus bersifat tauhidi, sebagai refleksi dari insan kamil di satu sisi, dan sebagai medium terpenting mencetak generasi insan kamil itu sendiri di sisi yang lain.

\section{B. Figur Insan Kamil dalam Pendidikan Islam}

Para sarjana Muslim meyakini bahwa profil pendidikan Islam berkiblat pada diri Baginda Nabi Muhammad saw. Sebab beliau merupakan sosok Manusia Sempurna atau Manusia Universal (al-insān al-kullīatau al-insān al-kāmil), yang diikuti oleh semua Nabi dan para hamba pilihan-Nya, yaitu para aulia dan ulama yang ilmu dan pemahaman spiritualnya sangat mendalam. Insan kamil sendiri didefinisikan sebagai seseorang yang sanggup menampakkan sifat-sifat Ketuhanan dalam perilakunya dan betul-betul menghayati kesatuan esensialnya dengan wujud Ilahiah tanpa harus kehilangan identitasnya sebagai seorang hamba dan makhluk-Nya. ${ }^{5}$ Ada juga yang berpendapat bahwa insan kamil adalah nama yang dipergunakan oleh kaum sufi untuk menamakan seorang Muslim yang telah sampai pada tingkatan tertinggi, yakni Fanā' $f \grave{\imath}$ Allāh. ${ }^{6}$

Mencapai maqām tersebut adalah sebuah keniscayaan. Sebab manusia merupakan tempat TajallīTuhan yang paling sempurna. Di mana ia adalah alam kecil (mikrokosmos) yang tercermin padanya alam besar (makrokosmos). Sehingga tergambar padanya Sifat-Sifat Ketuhanan. Untuk itulah manusia

5 Baca Wan Daud, The Educational Philosophy and Practice of Syed Muhammad Naquib Al-Attas..., p. 175; Gibs \& Kramers, Shorter Encyclopedia of Islam, (Leiden: E.J. Brill, 1965), 170; Muhammad Yusuf Musa, Falsafah al-Akhlaq fi al-Islam, cet. 3, (Kairo: Muassasat al-Khaniji, 1963), 266. 
diangkat sebagai khalifah di bumi. ${ }^{7}$ Dengan kata lain, seseorang menjadi insan kamil adalah semata karena ia telah menerima pancaran Sifat-Sifat Ilahiyah yang sempurna. ${ }^{8}$

Universitas Islam yang benar-benar Islami harus merefleksikan sosok manusia dan manusia harus merefleksikan Sifat-sifat Tuhan sebagaimana penjelasan tersebut. ${ }^{9}$ Manusia sendiri bisa mencapai kesempurnaan dan kebahagiaan hidup dengan melakukan penyesuaian diri terhadap kesempurnaan Tuhan dan menghiasi diri dengan makna Sifat-sifat Tuhan sebanyak mungkin. ${ }^{10}$ Ini artinya manusia harus mampu mengatur permasalahan internal dirinya sendiri sekaligus masyarakatnya sebagaimana Tuhan mengatur seluruh alam semesta. Sementara itu secara intrinsik pengaturan Tuhan terhadap alam semesta berhubungan dengan penciptaan alam semesta dengan haqq (bi alhaqq), yang itu merefleksikan kesempurnaan Pengetahuan dan Keadilan-Nya. Dengan demikian, sebagai refleksi dari insan kamil dalam wujud dan tujuannya, universitas Islam seharusnya memberikan perhatian pada masalah haqq. ${ }^{\text {" }}$

Hal itu menunjukkan bahwa dalam peradaban Islam, konsepsi tentang universitas yang benar-benar Islami sebagai sebuah refleksi dari insan kamil atau manusia universal tidak saja signifikan, namun juga riil. Sebab figur seperti baginda Nabi Muhammad saw adalah contoh riil insan kamil dan universal tersebut. Jika tidak, maka penekanan akan konsepsi ini justru akan mendorong kita terjerumus ke dalam suatu humanisme sofistik, seperti apa yang digambarkan oleh ungkapan Protagoras: "Manusia adalah ukuran dari segala sesuatu”. Untuk itu, universitas dalam Islam harus merefleksikan figur Nabi Muhammad saw dalam hal ilmu pengetahuan dan amal shalih. Sehingga

7 Abd. Qadir Mahmud, Al-Falsafah al-Șūfiyyah fì al-Islām, (Dār al-Fikr al-'Arabī, tt.), 575.

8 Abd. Al-Karim Ibn Ibrahim al-Jili, al-Insān al-Kāmil fì Ma'rifat al-Awākhir wa al-Awāàil, (Dār al-Fikr, tt.), 74 .

9 Wan Daud, The Educational Philosophy and Practice of Syed Muhammad Naquib Al-Attas..., p. 177.

10 Al-Ghazali, Al-Maqșad Al-Asnā fi Sharḥ Asma' Allāh al-Husnā. Terjemahan dan catatan oleh David Burrel dan Nazih Daher. The Ninety-Nine Beautiful Names of God, (Cambridge: Islamic Texts Society, 1992), 3 o dst.

11 Wan Daud, The Educational Philosophy and Practice of Syed Muhammad Naquib Al-Attas..., p. $177-178$. 
terbentuk manusia yang beradab yang memiliki kualitas seperti Nabi saw sesuai dengan kemampuan dan potensinya masing-masing. ${ }^{12}$

Sementara di Barat, konsep manusia universal hanya sebatas konsep. Sebab ide tersebut tidak mengakar pada figur yang pernah hidup dalam sejarah. Ditambah lagi ukuran-ukuran mereka tentang sesuatu yang ideal selalu berubah dan berevolusi. ${ }^{13}$ Di samping itu, menjadikan Nabi saw sebagai model dan pembimbing akan mengurangi kemungkinan adanya konflik generasi, seperti yang ada di Barat antara pelajar junior dan sarjana senior pada kurun yang bersamaan atau berbeda. ${ }^{14}$ Untuk itu Al-Attas mengkritik universitasuniversitas Muslim modern yang meniru begitu saja model sukuler Barat yang jelas-jelas merupakan refleksi dari sebuah negara, termasuk di dalamnya, manusia sekuler. ${ }^{15}$ Jadi sekalipun berusaha menyerupai manusia, ia bukanlah manusia sesungguhnya, namun sosok manusia sekuler. Al-Attas menjelaskan:

Bagaikan manusia tanpa kepribadian, universitas modern tidak memiliki pusat penting yang menyatukan, tidak memiliki prinsip dasar yang permanen sebagai tujuan akhirnya. Ia masih berpura-pura memikirkan sesuatu yang universal, bahkan mengaku memiliki pelbagai fakultas dan jurusan seolah-olah merupakan kesatuan dari anggota tubuh-tetapi tidak memiliki otak, apalagi akal dan jiwa, kecuali hanya sepenuhnya menurut fungsi administratif untuk perbaikan dan perkembangan fisik... Perbagai fakultas dan jurusan di dalamnya tidak saling bekerja sama, masing-masing sibuk dengan keinginannya, dengan kebebasan berkehendak mereka. ${ }^{16}$

\section{Pandangan Hidup Islam (Islamic Worldview) Asas Ilmu dan Pendidikan}

12 Wan Daud, The Educational Philosophy and Practice of Syed Muhammad Naquib Al-Attas..., p. 178-179.

13 Baca misalnya John Henry Newman, The Idea of a University Difined and Illustrated, edisi 1873, (London: Routledge \& Thoemmes Press, 1994), 120; Werner Jaeger, Paideia: The Ideals of Greek Culture, 3 jil. Diterjemahkan oleh Gilbert Highet, edisi ke-2, (New York/Oxford: Oxford University Press, 1945), I: xxii-xxiv; dan J.H. Randall Jr., The Making of the Modern Mind, edisi ulang tahun ke-5o. Kata pendahuluan oleh Jacques Barzun, (New York: Columbia University Press, 1976), 135-136.

14 Wan Daud, Islam and Secularism..., p. 86-9o.

15 Wan Daud, The Educational Philosophy and Practice of Syed Muhammad Naquib Al-Attas..., p. 192.

16 Al-Attas, Aims and Objectives..., p. 38-39. 
Dalam Islam, ilmu pengetahuan terbentuk dan bersumber dari pandangan hidup Islam (islamic worldview), yang berkaitan erat dengan struktur metafisika dasar Islam yang telah terformulasikan sejalan dengan wahyu, hadis, akal, pengalaman dan intuisi. ${ }^{17}$ Dalam hal ini worldview Islam merupakan pandangan Islam tentang realitas dan kebenaran yang nampak oleh mata hati kita dan yang menjelaskan hakekat wujud. Dan oleh karena apa yang dipancarkan Islam adalah wujud yang total, maka worldview Islam berarti pandangan Islam tentang wujud (ru'yat al-Islām li al-wujūd). ${ }^{18}$

Jadi secara mendasar worldview Islam adalah "visi tentang realitas dan kebenaran, berupa kesatuan pemikiran yang arsitektonik, yang berperan sebagai asas yang tidak nampak (non-observable) bagi semua perilaku manusia, termasuk aktivitas ilmiah dan teknologi". ${ }^{19}$ Sehingga setiap aktifitas manusia akhirnya dapat dilacak dari pandangan hidupnya, atau aktifitas manusia itu dapat direduksi kedalam pandangan hidup itu. ${ }^{20}$ Dan karena ilmu pengetahuan berkaitan erat dengan pandangan hidup, maka yang perlu diperhatikan oleh lembaga pendidikan Islam adalah penanaman elemen-elemen pandangan hidup Islam kedalam kurikulum pendidikan. ${ }^{21}$

17 al-Attas, A Commentary on the Hujat al-ØsiddÊ q of NËr al-DÊn al-RÉnirÊ: being an exposition of the salient point of distinction between the position of the theologians, the philosophers, the Sufi dan the pseudo-Sufi on the ontological relationship between God and the world and related questions, Ministry of Education and Culture, Kuala Lumpur, 1986, 464-465.

18 S.M.N, al-Attas dalam Prolegomena to The Metaphysics of Islam An Exposition of the Fundamental Element of the Worldview of Islam, Kuala Lumpur, ISTAC, 1995, 2

19 Alparslan Acikgence, Islamic Science, Towards Definition, Kuala Lumpur, ISTAC 1996, 29; baca juga dalam karyanya yang lain, Alparslan Acikgence, "The Framework for A history of Islamic Philosophy", Al-Shajarah, Journal of The International Institute of Islamic Thought and Civlization, (ISTAC, 1996, vol.1. Nos. 1\&2, 6. Teks aslinya: The foundation of all human conduct, including scientific and technological activities.

20 Alparslan Acikgence, "The Framework for A history of Islamic Philosophy", Al-Shajarah, Journal of The International Institute of Islamic Thought and Civlization, (ISTAC, 1996, vol.1. Nos. 1\&2, 6.

21 Hamid Fahmy Zarkasyi, Pandangan Hidup, Ilmu Pengetahuan dan Pendidikan Islam, makalah disampaikan pada workshop Ilmu Pengetahuan dan Pendidikan di Sekolah Tinggi Lukman ul Hakim, Hidayatullah Surabaya, 12-13 Agustus 2005, p. 10. 
Elemen utama pandangan hidup Islam adalah kepercayaan terhadap Tuhan. ${ }^{22}$ Karena itu, Islam menerima pengetahuan non-empiris. Sebaliknya, pandangan hidup yang mengingkari eksistensi Tuhan akan menafikan pengetahuan nonempiris dan pengetahuan spiritual lainnya. Contohnya pandangan hidup ateis akan menganggap sumber pengetahuan moralitasnya sebatas subyektifitas manusia saja, bukan Tuhan. ${ }^{23}$ Dengan demikian, bentuk pendidikan dan corak ilmu pengetahuan Islam ditentukan oleh karakter pandangan hidup Islam itu sendiri. Sebaliknya pembentukan ilmu pengetahuan yang bersumber pandangan hidup Islam itu terjadi melalui proses pendidikan.

Mengingat hubungan pandangan hidup Islam dan bentuk pendidikan Islam tersebut, maka pemahaman dan implementasi nilai-nilai tauhid dalam kurikulum pendidikan adalah sebuah keniscayaan. Sayyid Qutb misalnya menegaskan ke-taqwa-an kepada Tuhan dan keyakinan kepada Keesaan Tuhan (tawhìd) menjadi prinsip paling asasi dari peradaban Islam. ${ }^{24}$ Oleh sebab itu dalam kitab Ihy $\bar{a}^{\prime}$ Al-Ghazali menegaskan bahwa setiap orang yang mengaitkan segala sesuatu kepada Allah swt, niscaya ia akan menjadi orang yang berpaham teguh, mengetahui kebenaran dan hakikat. ${ }^{25}$ Dengan kata lain substansi peradaban Islam adalah pokok-pokok ajaran Islam yang tidak terbatas pada sistem kepercayaan, tata pikir, dan tata nilai semata, akan tetapi merupakan super-sistem yang meliputi keseluruhan pandangan tentang wujud,

22 Menurut Al-Attas, elemen asas worldview Islam adalah konsep tentang hakekat Tuhan, Wahyu (al-Qur'an), penciptaan, hakekat kejiwaan manusia, ilmu, agama, kebebasan, nilai dan kebajikan, dan tentang kebahagiaan. Baca S.M.N, al-Attas, "The Worldview of Islam, An Outline, Opening Adress", dalam Sharifah Shifa al-Attas ed. Islam and the Challenge of Modernity, Proceeding of the inaugural Symposium on Islam and the Challenge of Modernity: Historical and Contemporary Context, Kuala Lumpur Agustus, 1-5, 1994, ISTAC, Kuala Lumpur, 1996, hal. 29. Bandingkan dengan pandangan Thomas Wall dalam karyanya Thinking Critically About Philosophical Problem, A Modern Introduction, Wadsworth, Thomson Learning, Australia, 2001, p. 16; dan Ninian Smart, pakar kajian perbandingan agama, dalam karyanya: Worldview, Crosscultural Explorations of Human Belief, Charles Sribner's sons, New York, n.d., p. 8-9.

23 Lihat Thomas F Wall, Thinking About Philosophical Problem, Wadsworth, Thomson Learning, United States, hal. 126-127

24 Dikutip oleh Muhammad Abdul Jabbar Beg, dalam The Muslim World League Journal, edisi November-Desember, 1983, p. 38-42.

25 Al-Ghazali, Ihyya ' 'Ulüm al-Dìn, Juz IV, ...p. 2930; bandingkan dengan karyanyayang lain, Mukāshafat al-Qulüb, ...p. 272-273. 
khususnya pandangan tentang Tuhan. ${ }^{26}$ Apalagi sumber dari semua ilmu adalah Allah swt, ${ }^{27}$ yang menjadikan ilmu bersifat tidak terbatas (limitless)..$^{28}$

\section{Peran Universitas Mencetak Manusia Beradab}

Sejatinya strategi penekanan pada pendidikan universitas atau pendidikan masyarakat dewasa ${ }^{29}$ adalah pilihan para Nabi. Dalam hal ini universitas menjadi medium terpenting pengembangan suatu peradaban. Di dalamnya pengembangan ilmu pengetahuan bisa maksimal dan calon-calon pemimpin bangsa dan umat dicetak. ${ }^{30}$ Ini adalah interpretasi yang benar terhadap hikmah ilahiah (divine wisdom) yang menjadikan pendidikan orang dewasa sebagai target misi semua Nabi. Hal ini selanjutnya menjadi karakteristik pokok masyarakat Islam dan telah menjadi perhatian utama para pemikir Musim sejak dahulu hingga adanya modernitas yang lebih menekankan pada pendidikan dasar dan menengah lanjutan.

Dengan demikian penekanan pada pendidikan tinggi terutama universitas bukanlah cermin pemikiran kaum elitis yang merupakan karakteristik

26 Hamid Fahmy Zarkasyi, Membangun Peradaban Islam Yang Bermartabat (Gontor, CIOS, 2009), p. 14; selanjutnya, uraian luas dan serius mengenai ilmu dan hal-hal yang berkaitan dengannya bisa dilihat dalam kitab Al-Ghazali, Ihyyā' 'Ulūm al-Dīn, juz. I (Damaskus: Dār Al-Fikr, 1427 H/2006 M), 43-212.

27 Al-Attas, Prolegomena..., p. 118 \& 182; The Intuition of Existence: A Fundamental Basis of Islamic Metahpysics, (Kuala Lumpur: International Institute of Islamic Thought and Civilization International Islamic University, 199o), 7; Islam, Secularism and the Philosophy of the Future, ..., p. 211; dan Islam \& Filsafat Sains, (Bandung: Mizan, 1995), 34.

28 Al-Attas, Islam and Secularism, ..., p. 144; Islam dan Filsafat Sains, ..., p. 43-44. lihat juga uraian Wan Daud dalam bukunya The Educational Philosophy and Practice of Syed Muhammad Naquib AlAttas..., p. 101, 104 \& 114. Kenyataan ilmu tidak terbatas tidak lantas berimplikasi pada pemahaman bahwa proses pencarian ilmu adalah tanpa akhir. Sebab ada suatu batas kebenaran dalam setiap objek ilmu, dan setiap objek ilmu memiliki batas kebenaran yang berbeda. Lihat Al-Attas, Prolegomena..., p. 134-135; dan Islam dan Filsafat Sains, ..., p. 63-65.

29 Masa dewasa, dimulai sejak balig (pubertas) dalam Islam, ditentukan oleh faktor-faktor perkembangan fisik dan jenjang usia. Menurut Madzhab Hanafi, Syafi'i, dan Hanbali, usia balig untuk kedua jenis kelamin adalah 15 tahun. Sementara menurut Madzhab Maliki usia balig adalah umur 18 tahun. Namun boleh jadi sudah memasuki usia balig setelah umur 9 tahun jika sesorang anak laki-laki mengalami mimpi basah dan untuk perempuan terjadinya menstruasi. Baca C.E. Bosworth, E. Van Donzel, B. Lewis, Charles Pellat, eds., Encyclopaedia of Islam, edisi baru, (Leiden: E.J. Brill, 1986), entri "balig". 
masyarakat feodal yang didasarkan pada keadaan sosial-ekonomi. ${ }^{31}$ Sebaliknya penekanan pada pendidikan menengah merupakan warisan penjajah sebagaimana kesimpulan Al-Attas. Penjajah memberikan penekanan pada pendidikan menengah agar tidak lahir pemimpin-pemimpin yang tangguh yang dapat membahayakan politik penjajah. Sebaliknya mereka bisa memproduksi pegawai-pegawai kolonial. ${ }^{22}$

Atas dasar itu, jika sistem pendidikan tinggi terutama universitas tidak direformasi sesuai dengan kerangka epistemologi dan pandangan hidup Islam, maka reformasi pendidikan melalui penekanan pada pendidikan dasar dan menengah lanjutan akan gagal. Sebaliknya jika pendidikan yang benar dapat diberikan di tingkat tertinggi yaitu dalam bentuk ta'dīb, maka berbagai kekurangan yang ada pada pendidikan tingkat rendah dapat diperbaiki. ${ }^{33} \mathrm{Jika}$ demikian, maka dapat dikatakan bahwa masalah yang melanda Dunia Muslim beberapa abad belakangan ini bersumber dan tercermin pada institusi-institusi pendidikan tinggi mereka. ${ }^{34}$

\section{E. Ta'dīb sebagai Pendidikan Islam}

Menurut Al-Attas, jika dikaji secara mendalam, konsep yang paling tepat untuk pendidikan Islam adalah ta'dīb, bukan tarbiyah ataupun ta'limm. Sebab struktur konsep ta'dīb sudah mencakup unsur ilmu ('ilm), instruksi (ta'lim), dan pembinaan yang baik (tarbiyah). Sehingga tidak perlu lagi dikatakan bahwa konsep pendidikan Islam adalah sebagaimana yang terdapat dalam tiga serangkai konotasi tarbiyah, ta'lìm, dan ta'dīb. ${ }^{35}$

Istilah tarbiyah hanya menyinggung aspek fisikal dalam mengembangkan tanam-tanaman, dan hanya terbatas pada aspek fisikal emosional dalam pertumbuhan dan perkembangan binatang. ${ }^{6}$ Oleh sebab itu tarbiyah hanya berkaitan dengan pengembangan fisikal dan emosional daripada manusia.

\footnotetext{
$31 \quad$ Ibid., p. 169-170.

32 Hamid Fahmy Zarkasyi, "Peran Sentral Universitas Islam", Jurnal ISLAMIA, Vol. III, Non. 3, 2008, p. 5 .

33 Wan Daud, The Educational Philosophy and Practice of Syed Muhammad Naquib Al-Attas..., p. 170.

34 Ibid., p. 171.

35 Al-Attas, The Concept of Education in Islam (selanjutnya disingkat CEEI), p. 34.

36 Al-Attas, CEEI, p. 29. Lihat keterangan lebih lanjut dalam Hans Wehr, Arabic-English Dictionary, edited by J.M. Cowan, edisi ketiga (Ith-aca: Spoken Languages Services, 1976), "rabba".
} 
Makanya Fir'aun dapat mengatakan bahwa dirinya telah melaksanakan tarbiyah kepada Nabi Musa as (Lihat QS. 28: 18). Sementara talim secara umum hanya terbatas pada pengajaran dan pendidikan kognitif. Dan istilah keduanya sudah tercakup di dalam makna $t a^{\prime} d \bar{l} b{ }^{37}$

Walaupun Al-Qur'an tidak memakai istilah adab ataupun istilah lain yang mempunyai akar kata yang sama dengannya, perkataan adab itu sendiri dan cabang-cabangnya disebutkan dalam ucapan-ucapan Nabi saw, para sahabat r.a., dalam puisi ataupun karya sarjana-sarjana Muslim yang datang setelah mereka. ${ }^{38}$ Bahkan ada Hadis yang berbunyi: "Tuhan telah mendidikku (addabanī, yang bermakna telah menanamkan adab pada diriku), maka sangat baiklah mutu pendidikanku $\left(t a^{\prime} d \bar{\imath} b \bar{\imath}\right)^{39}$. Karena itu, Nabi Muhammad saw adalah figur ideal bagi orang yang beradab sebagaimana digambarkan dalam Al-Qur'an, seperti dalam QS. al-Qalam (68): 4; al-Aḩzāb (33): 21; Al-H<ujurāt (49): 13; dan Saba' (34): 28.

Untuk itu Al-Attas kemudian merumuskan tujuan pendidikan untuk menciptakan individu yang baik, yakni seorang manusia beradab dalam pengertian yang komprehensif, bukan untuk menghasilkan warga negara yang baik dan tidak pula pekerja yang baik. ${ }^{40} J a d i$ yang ditekankan dalam pendidikan Islam adalah nilai manusia sebagai manusia sejati, sebagai warga dari kota yang terdapat dalam dirinya, sebagai warga negara dalam kerajaannya yang mikro, sebagai sesuatu yang bersifat spiritual. Jadi pendidikan Islam tidak menekankan pada nilai manusia sebagai entitas fisik yang diukur dalam konteks pragmatis dan utilitarian berdasarkan kegunaannya bagi negara, masyarakat dan dunia. ${ }^{41}$

Sebab jika orientasi pendidikan adalah menciptakan warga negara atau pekerja yang baik dalam sebuah negara sekular, maka hal itu tidak otomatis

37 Haddad, Arab's Theory of Instruction, p. 242-243; dan Al-Attas,CEEI, p. 28-33; Islam and Secularism, p. 144-145; catatan 123 .

38 Sedikitknya terdapat 18 entri tentang ta'dīb, addaba dan adab, yang bisa dijumpai dalam lebih dari satu koleksi Hadis. Lihat A.J. Wensinck and J. HLM. Mensing, Concordance, 7, vo. (Leiden: E.J. Brill, 1943), I: 26; Nasrat Abdel Rahman, "The Semantics of Adab in Arabic, Al-Shajarah, Vol. 2. No. 2, 1997, p. 189-207.

40 Wan Daud, The Educational Philosophy and Practice of Syed Muhammad Naquib Al-Attas..., p. 225.

41 Al-Attas, Islam and Secularism, (Kuala Lumpur: Angkatan Belia Islam Malaysia, 1978); cet. kedua dengan pengantar baru oleh ISTAC, 1993, p. 141. 
sama dengan manusia yang baik. Sebaliknya, manusia yang baik sudah pasti seorang pekerja dan warga negara yang baik. ${ }^{42}$ Lebih lanjut Al-Attas menjelaskan:

"Penekanan terhadap individu mengimplikasikan ... pengetahuan tentang akal, nilai dan spirit, dan tentang tujuan dan maksud yang sebenarnya [dari kehidupan ini], sebab akal, nilai dan spirit adalah unsur-unsuryang inheren dalam setiap individu... [Sedangkan] penekanan terhadap masyarakat dan negara...membuka pintu yang menuju kepada legalitas dan politik. ${ }^{43}$

Penjelasan Al-Attas tersebut juga menyiratkan bahwa penekanan terhadap pendidikan individu daripada masyarakat atau negara adalah karena hal itu lebih prinsip dan dasar dalam proses membangun kembali peradaban Islam. Terlebih ketika saat ini hampir seluruh negara termasuk negara-negara Muslim menerima dan menjadikan sekularisasi sebagai agenda filsafat yang ditempuh melalui proses 'disenchantment' alam, yakni dengan menghilangkan semua unsur dan makna spiritual dari alam, dengan cara mendesakralisasikan politik, dekonsekrasi (deconsecration) dan relativisasi nilai, ${ }^{44}$ maka pilihan menekankan terhadap pendidikan individu bukan hanya sesuatu yang prinsipil, tetapi juga strategi yang tepat. ${ }^{45}$

Namun demikian, pengembangan individu tidak dapat dipisahkan secara sosial dalam cara dan konteks pelaksanaannya. Tidak ada pemisahan antara individu dan masyarakat dalam persaudaraan kemanusiaan, bukan saja dari tinjauan kontrak sosial secara historis yang telah terjadi, tetapi dari tinjauan Ikatan Primordial yang sudah terjadi antara seluruh manusia yang diciptakan oleh Allah swt. Hal ini bisa dilihat dalam Firman-Nya QS. Al-A'rāf (7): 172, dimana di situ manusia untuk pertama kali menyatakan dirinya dengan katakata plural (jama'), yakni balā shahidnā(ya, kami menyaksikan). Ini berarti

42 Al-Attas, Risalah Untuk Kaum Muslimin, (Kuala Lumpur: ISTAC, 2001), p. 41; ISLAM: The Concept of Religion and The Foundation of Ethics and Morality, p. 33-34; Aims and Objectives of Islamic Education, ed. S.M.N. al-Attas, (London:/Jeddah:Hodder \& Stoughton/King Abdul Aziz University, 1979), p. 32-33.

43 Al-Attas, Aims and Objectives, p. 6.

44 Al-Attas, Address of Acceptance of Appointment to the al-Ghazali Chair of Islamic Thought," Commemorative Volume on the Conferment of the al-Ghazali Chair of Islamic Thought on Prof. Dr. Syed Muhammad Naquib al-Attas, (Kuala Lumpur: ISTAC, 1994), 27-28.

45 Al-Attas, Aims and Objectives..., p. 6. 
setiap ruh menyatakan dirinya secara individual dalam hubungannya dengan yang lain dan juga dengan Tuhan mereka. ${ }^{46} \mathrm{Al}$-Attas menjelaskan:

"Ketika kami menyatakan bahwa tujuan daripada ilmu pengetahuan adalah melahirkan manusiayang baik, bukanlah berarti bahwa kami tidakbermaksud untuk melahirkan masyarakat yang baik, sebab masyarakat adalah terdiri daripada individu, maka melahirkan seseorang akan melahirkan masyarakat yang baik. Pendidikan adalah (pembuat) struktur masyarakat".47

Perlu dijelaskan bahwa makna 'baik' dari tujuan pendidikan Islam adalah adab dalam artian yang menyeluruh, yang meliputi kehidupan spiritual dan material sesorang, yang berusaha menanamkan kwalitas kebaikan yang diterimanya. ${ }^{48} \mathrm{Adab}$ sendiri Al-Attas definisikan sebagai "pengenalan dan pengakuan terhadap realitas bahwasanya ilmu dan segala sesuatu yang ada terdiri dari hirarki yang sesuai dengan kategori-kategori dan tingkatantingkatannya, dan bahwa seseorang itu mempunyai tempatnya masing-masing dalam kaitannya dengan realitas tersebut dan dengan kapasitas serta potensi fisik, intelektual dan spiritualnya. ${ }^{49}$

Di situ tampak bahwa adab mensyaratkan ilmu pengetahuan dan metode mengetahui yang benar. Sehingga mampu menjaga manusia dari kesalahan penilaian dan perbuatan. Akhirnya ia mampu memposisikan dirinya pada tempat yang benar dan sesuai. Dan ilmu pengetahuan yang bisa mendorong lahirnya sikap seperti itu adalah kebijaksanaan (hikmah) yang menghasilkan keadilan pada diri individu dan negara, masyarakat, dan alam sekitarnya..$^{50}$

Di sinilah kenapa Al-Attas juga mendefinisikan pendidikan Islam sebagai pengenalan dan pengakuan mengenai tempat sesuatu sesuai dengan tatanan penciptaan yang ditanamkan secara progresif ke dalam diri manusia. Sehingga

46 Al-Attas, Risalah Untuk Kaum Muslimin..., p. 31-32 \& 38; dan Islam and Secularism..., p. 69-70.

47 Al-Attas, The Concept of Education in Islam..., p. 25.

48 Al-Attas, Aims and Objectives, p. 1; The Concept of Education in Islam..., p. 23.

49 Al-Attas, The Concept of Education in Islam..., p. 27.

50 Kemungkinan sumber lain yang mengilhaminya untuk menghasilkan pandangan yang signifikan dan luas tersebut adalah berkat keutamaan (fadīlah) hikmah, kontrol-diri ('iffah), keberanian (shajä'ah), dan keadilan ('adl) yang dibimbing oleh agama. Baca Al-Attas, Prolegomena to the Metaphysics of Islam: An Exposition of the Fundamental Elements of the Worldview of Islam, (Kuala Lumpur: ISTAC, 1995), 92, 94-104. 
tercapai pengenalan dan pengakuan Tuhan dalam tatanan wujud dan maujud..$^{1}$ Jadi pendirian lembaga-lembaga pendidikan dan artikulasi mengenai target dan tujuan pendidikan tidak boleh didasarkan pertimbangan sosial-ekonomi, politis, dan birokratis semata, tetapi lebih berpijak pada nilai-nilai religius yang murni dan mendalam..$^{2}$

Sampai di sini bisa dipahami bahwa orang terpelajar dalam perspektif Islam adalah orang yang beradab. ${ }^{53}$ Yakni Muslim yang terdidik secara benar, jelas identitasnya, jujur, moderat, berani, dan adil dalam menjalankan kewajibannya dalam berbagai realitas dan masalah kehidupan sesuai dengan urutan prioritas yang dipahaminya. ${ }^{54}$ Dalam keadaan demikian ia telah menyadari sepenuhnya akan tanggungjawab dirinya kepada Tuhan yang haq, yang memahami dan menunaikan kewajiban terhadap dirinya sendiri dan orang lain yang terdapat dalam masyarakatnya, yang selalu berupaya meningkatkan setiap aspek dalam dirinya menuju ke arah kesempurnaan sebagai manusia yang beradab. ${ }^{55} \mathrm{jika}$ demikian halnya, seorang yang terdidik (beradab) tidak lain manusia universal yang memahami dan mengamalkan adab dalam diri, keluarga, lingkungan, dan masyarakat dunia..$^{5}$

\section{F. Kurikulum Tauhidi Pendidikan Tinggi Islam}

Perencanaan, isi, dan metode pendidikan harus mencerminkan penekanan pada pengamalan adab yang benar secara disiplin dan konsisten dalam berbagai tingkat relitas. Tujuan ini harus dimulai realisasinya melalui sistem pendidikan yang baru diformulasikan dan dilaksanakan di negara Muslim pada tingkat universitas. ${ }^{57}$ Struktur dan kurikulum tersebut kemudian secara bertahap diaplikasikan pada tingkat pendidikan rendah. ${ }^{8}$ Kurikulum ini sendiri secara

$5^{1} \quad$ Al-Attas, The Concept of Education in Islam..., p. 27.

$5^{2}$ Wan Daud, The Educational Philosophy and Practice of Syed Muhammad Naquib Al-Attas..., p. 199.

53 Al-Attas, The Concept of Education in Islam..., p. 22-27; Islam and Secularism..., p. 142-143; dan Risalah, paras.53-55, p. 179-187.

54 Wan Daud, The Educational Philosophy and Practice of Syed Muhammad Naquib Al-Attas..., p. 165.

55 Al-Attas, Risalah Untuk Kaum Muslimin..., p. 54.

56 Wan Daud, The Educational Philosophy and Practice of Syed Muhammad Naquib Al-Attas..., p. 166-167.

57 Wan Daud, The Educational Philosophy and Practice of Syed Muhammad Naquib Al-Attas..., p. 167.

$5^{8}$ Al-Attas, Islam and Secularism..., p. $15^{2}$. 
mendasar diambil dari hakikat manusia yang besifat ganda (dual nature); aspek fisikal yang lebih berhubungan dengan pengetahuannya tentang ilmuilmu fisikal dan teknikal, atau farḍifāyah; dan kedua, keadaan spiritual yang sebagaimana terkandung dalam istilah-istilah rūh, nafs, qalb, dan 'aql, lebih tepatnya berhubungan dengan ilmu inti atau fard 'ayn. 59

Sebab bagaimanapun, ilmu pengetahuan yang dapat memenuhi kebutuhan manusia adalah yang memiliki dua aspek sekaligus: pertama, yang memenuhi kebutuhannya yang berdimensi permanen dan spiritual; dan kedua, yang memenuhi kebutuhan material dan emosional. ${ }^{6}$ Dalam hal ini, kategori ilmu fard 'ayn, misalnya, adalah aktualisasi dari dimensi-dimensi universal, permanen, personal, spiritual, dari tujuan pendidikan dan organisasi ilmu pengetahuan dan kurikulum. Sementara itu, kategorifard kifāyah merealisasikan aspek-aspek partikular, aspek yang berubah-ubah, aspek fisikal dan sosial yang tercermin dalam organisasi ilmu dan keseluruhan kurikulum. ${ }^{61}$

Pada tingkat perguruan tinggi, kandungan umum dari kategori ilmu-ilmu fard 'ayn adalah kitab suci Al-Qur'an (pembacaannya dan interpretasinya), Sunnah, syari'at (fiqih dan hukum), Teologi (ilmu Kalam), Metafisika Islam (psikologi, kosmologi dan ontologi), dan ilmu bahasa (bahasa Arab, tata bahasanya, leksikografi, dan sastra). Sementara kandungan umum dari ilmuilmu faṛ̂ kifāyah adalah ilmu kemanusiaan, ilmu alam, ilmu terapan, ilmu teknologi, perbandingan agama, kebudayaan barat, ilmu linguistik (bahasa Islam), dan sejarah Islam. ${ }^{62}$ Pembagian ilmu farḍ 'ayn dan fard kifāyah tersebut tidak perlu dipahami secara dikotomis. Sebab ia hanyalah pembagian hirarki ilmu pengetahuan berdasarkan kepada tingkat kebenarannya. Oleh sebab itu, ia harus dilihat sebagai kesatuan integral atau tauhidi. Dimana yang pertama merupakan asas dan rujukan bagi yang kedua. ${ }^{63}$

59 Al-Attas, Islam and Secularism..., p. 149-152; dab The Concept of Education in Islam..., p. 40-43.

6o Wan Daud, The Educational Philosophy and Practice of Syed Muhammad Naquib Al-Attas..., p. 240.

61 Ibid., p. 199.

62 Al-Attas, The Concept of Education in Islam..., p. 42-43; dan baca juga Wan Daud, The Educational Philosophy and Practice of Syed Muhammad Naquib Al-Attas..., p. 247-255.

63 Hamid Fahmy Zarkasyi, Peradaban Islam: Makna dan Strategi Pembangunannya, (Jawa Timur: CIOS ISID Gontor, 2010), 63. 
Ilmu pengetahuan fard 'ayn merupakan elemen yang menyatukan, ditambah metafisika sebagai bagian intinya. Dalam hal ini, organisasi dan peranan fakultas dalam universitas, penelitian, penerimaan, bahkan dalam menawarkan mata kuliah dan pengaturan waktunya seminar-seminar, dan beberapa aktivitas formal dan nonformal harus merefleksikan hal ini sedekat mungkin. ${ }^{64}$ Makanya jika tidak ada unsur kategori ilmu fardu ain yang memadai, maka kurikulum pendidikan bagi mahasiswa di bidang sains dan teknologi dan pendidikan universitas yang dijalankan oleh sektor-sektor swasta akan menjadi tragedi besar bagi individu dan bangsa bersangkutan.

Jadi salah satu ciri khas dari kurikulum pendidikan Islam adalah kejelasan akan kategori ilmu farḍ 'ayn dan fard kifäyah. Kategorisasi ini juga berkaitan erat dengan kewajiban manusia dalam menuntut ilmu dan mengembangkan adab. Sebab kewajiban tersebut berhadapan dengan kenyataan bahwa sifat ilmu yang tidak terbatas, sementara kehidupan manusia itu terbatas. ${ }^{65} \mathrm{Di}$ samping itu juga harus dipahami bahwa ada batasan kebenaran bagi setiap objek ilmu pengetahuan. Sehingga sesuatu yang kurang dan lebih dari batasan itu adalah sebuah kesalahan dan kebatilan. ${ }^{66}$ Menurut Al-Attas, sikap tersebut tidak bermakna bahwa ada batasan dalam mencari ilmu, sebab objek ilmu pengetahuan memiliki batasan yang berbeda-beda. ${ }^{67}$ Sikap tersebut justru mendorong sifat kejelasan dan ketepatan yang akan membuat proses pendidikan menjadi lebih jujur, terarah, praktis, dan lebih bermakna bagi orang yang mencarinya. ${ }^{68}$

Untuk itu pada tingkat tertinggi, Al-Attas mencangkan bahwa pendidikan universitas Islam seharusnya membentuk ilmuwan Muslim yang bukan spesialis sempit. Ia menjaskan: "Ilmuwan Muslim bukanlah seorang spesialis dalam cabang pengetahuan apap pun, melainkan universalis dalam cara pandangnya dan memiliki otoritas dalam beberapa cabang ilmuyang berkaitan." Spesialisasi

64 Wan Daud, The Educational Philosophy and Practice of Syed Muhammad Naquib Al-Attas..., p. 197.

65 Ibid., p. 243.

66 Ibid. 243.

67 Al-Attas, Prolegomena..., p. 134-135; baca juga Wan Daud, The Educational Philosophy and Practice of Syed Muhammad Naquib Al-Attas..., p. 243.

68 Wan Daud, The Educational Philosophy and Practice of Syed Muhammad Naquib Al-Attas..., p. $243-244$. 
seharusnya hanya dibolehkan setelah pelajar menguasai ilmu fard 'ayn, dan ini mencakup spesialisasi dalam cabang-cabang ilmu pengetahuan inti tertentu, seperti ilmu Al-Qur'an ('ulūm Al-Qur'ān) dan bahasa Arab, atau pengetahuan inti yang diharapkan bagi setiap Muslim dan Muslimah. ${ }^{69}$ Sementara dalam sistem pendidikan Muslim modern saat ini telah memberikan penekanan yang tidak semestinya pada pengetahuan fard kifāyah dengan mengabaikan penguasaan yang sepatutnya terhadapfard 'ayn. Hal itu karena mereka terlalu menekankan spesialisasi dan pembentukan warga negara dan pekerja yang berguna. $^{70}$

Keyakinan Al-Attas bahwa pendidikan tinggi tidak seharusnya mencetak para spesialis bukan berarti universitas tidak harus mencetak insinyur, dokter medis, ahli ekonomi, atau ahli komputer, dan bahkan ahli bahasa yang berkompeten. Sebab bagaimanapun bidang-bidang tersebut termasuk dalam berbagai subjek di bawah kategori farḍ kifāyah. Bahkan Al-Attas menegaskan bahwa spesialisasi itu harus ada, hatta dalam subjek fardu ain sekalipun, agar universitas bisa mencetak ahli teologi, ahli bahasa, dan ahli fikih yang andal.

Al-Attas juga tidak menafikan adanya 'ledakan ilmu pengetahuan'. AlAttas hanya menekankan bahwa seorang ilmuwan Muslim yang merupakan produk dari universitas Islam seharusnya mempunyai pengetahuan yang cukup tentang prinsip-prinsip, konsep-konsep, dan isu-isu penting dalam tradisi intelektual Islam dan ilmu-ilmu humaniora sehingga ilmuwan tersebut mampu memberikan kontribusi dan bertanggung jawab terhadap bidang ilmu yang ia pilih. ${ }^{71}$ Namun bagaimanapun Al-Attas menggarisbawahi bahwa konsep spesialisasi yang ia maksud tidak merujuk pada kebutuhan negara dan masyarakat sekuler. ${ }^{2}$

69 Al-Attas dalam Wan Daud, The Educational Philosophy and Practice of Syed Muhammad Naquib Al-Attas..., p. 257-258.

$70 \quad$ Ibid., p. 257.

71 Ibid., p. 258.

72 Al-Attas, The Concept of Education in Islam..., p. 44-45. Tidak hanya Al-Attas, ilmuwan Barat pun ada yang mengkritik konsep pendidikan yang menekankan pada spesialisasi. Baca misalnya Jose Ortega Y. Gassett, The Mission of the University. Disunting dan diterjemahkan oleh Howard Lee Nostrand, (New York:W.W. Norton, 1994), p. 38-39; Jacques Maritain, Education at the Crossroads, (New Haven dan London: Yale University Press, 1943), 19. 
Kembali pada tradisi masyarakat Barat yang cenderung menyama-ratakan kedudukan semua mata pelajaran, itu adalah salah satu bentuk dari pemikiran sofisme 'indiyyah. Dimana mereka mengorganisasi mata pelajaran yang di dalamnya semua disiplin ilmu pengetahuan dan mata pelajaran dianggap sama. Misalnya, kajian Teologi Islam dianggap sama pentingnya dengan ilmu-ilmu komputer atau bisnis. Padahal sebagaimana dijelaskan Al-Attas, ditinjau dari metafisika, semua mata pelajaran yang diajarkan tidak bisa diberi penekanan yang sama. Jika diperlakukan sama, maka itu adalah suatu ketidakadilan. Sebab penekanan terhadap mata pelajaran seharusnya diberikan sesuai dengan kedudukannya dalam perspektif Islam mengenai hierarki kepentingan dan prioritas ilmu pengetahuan. ${ }^{73}$

Selanjutnya, salah satu karakteristik dan epistemologi Islam yang dijelaskan secara mendalam dan dipraktekkan oleh Al-Attas adalah apa yang ia sebut sebagai Metode Tawhid dalam Ilmu Pengetahuan. ${ }^{74} \mathrm{Hal}$ ini didukung oleh kenyataan bahwa seluruh representasi tradisi Islam telah mengaplikasikan berbagai metode di dalam penyelidikan mereka, seperti religius dan ilmiah, empiris dan rasional, deduktif dan induktif, subjektif dan objektif, tanpa menjadikan salah satu metode lebih dominan dari yang lain. ${ }^{75}$ Metode ini menyelesaikan problematika dikotomi yang salah, seperti antara aspek objektif dan subjektif ilmu pengetahuan. Dalam metode tauhid ini dijelaskan bahwa yang objektif dan yang subjektif tidak dapat dipisahkan. Sebab keduanya adalah aspek dari realitas yang sama, sehingga satu sama lain saling melengkapi. ${ }^{76}$

Yang tidak kalah penting, Al-Attas menekankan bahwa pemimpin sebuah perguruan Tinggi atau universitas Islam haruslah orang yang memiliki otoritas dan kemampuan dalam berbagai cabang ilmu religio-humanistik. Jadi ia bukan hanya seorang ilmuwan atau seorang guru, melainkan juga seorang

73 Wan Daud, The Educational Philosophy and Practice of Syed Muhammad Naquib Al-Attas..., p. 93. Sofisme 'Indiyyah adalah mereka yang selalu bersikap subjektif. Kelompok ini menolak objektivitas ilmu pengetahuan dan kebenaran. Lihat Al-Attas, Commentary..., p. 206-207; baca juga Qosim Nursheha Dzulhadi, Jejak Sophisme dalam Liberalisasi Pemikiran di Indonesia, makalah disampaikan dalam bedah buku: Membongkar Kedok Liberalisasi di Indonesia, InPAS Surabaya, di Masjid Nuruzzaman Unair, 16 Februari 2013.

74 Al-Attas, Prolegomena..., p. 3.

75 Ibid.

76 Ibid., p. 3, catatan 2. 
pemimpin yang kuat dengan kemampuan administratif untuk mewujudkan sekaligus merepresentasikan ideal-ideal dan tradisi pendidikan Islam dalam berbagai bentuk institusi, demi menghadapi keadaan yang selalu berubah dan menantang. ${ }^{77}$

\section{G. Penutup}

Universitas akan melahirkan sarjana Muslim yang beradab manakala desain kurikulumnya merupak refleksi dari insan kamil, yakni bersifat tauhidi. Artinya ia merupakan kurikulum yang dibangun di atas sifat dasar manusia yang terdiri atas aspek fisikal dan spiritual sekaligus, yang dilihat sebagai satu kesatuan utuh. Selanjutnya organisasi dan peranan fakultas dalam universitas, penelitian, penerimaan, bahkan dalam menawarkan mata kuliah dan pengaturan waktunya seminar-seminar, dan beberapa aktivitas formal dan nonformal harus merefleksikan hal ini sedekat mungkin. Dengan demikian universitas menjadi medium menanamkan adab dalam diri untuk meniru sedekat mungkin pribadi Nabi Muhammad saw. Sehingga lahir sarjana Muslim yang universalis dalam cara pandangnya dan memiliki otoritas dalam beberapa cabang ilmu yang berkaitan. Wa Allāh A'lam bi al-ṣawāb.

77 Wan Daud, The Educational Philosophy and Practice of Syed Muhammad Naquib Al-Attas..., p. 192. 


\section{DAFTAR PUSTAKA}

Abdullah, Fatimah, "Konsep Islam Sebagai Din: Kajian Terhadap Pemikiran Prof. Dr. SMN. Al-Attas", ISLAMIA, Thn I, no. 3, September-November 2004. Acikgence,Alparslan,Islamic Science, Towards Definition, Kuala Lumpur, ISTAC 1996.

Acikgence,Alparslan, "The Framework for A history of Islamic Philosophy", Al-Shajarah, Journal of The International Institute of Islamic Thought and Civlization, (ISTAC, 1996, vol.1. Nos. 1\&2, 6.

Al-Attas, "The Worldview of Islam, An Outline, Opening Adress", dalam Sharifah Shifa al-Attas ed. Islam and the Challenge of Modernity, Proceeding of the inaugural Symposium on Islam and the Challenge of Modernity: Historical and Contemporary Context, Kuala Lumpur Agustus, 1-5, 1994, ISTAC, Kuala Lumpur, 1996.

Al-Attas, A Commentary on the Hujat al-ØsiddÊ q N an exposition of the salient point of distinction between the position of the theologians, the philosophers, the Sufi dan the pseudo-Sufi on the ontological relationship between God and the world and related questions, Ministry of Education and Culture, Kuala Lumpur, 1986.

Al-Attas, Address of Acceptance of Appointment to the al-Ghazali Chair of Islamic Thought," Commemorative Volume on the Conferment of the al-Ghazali Chair of Islamic Thought on Prof. Dr. Syed Muhammad Naquib al-Attas. Kuala Lumpur: ISTAC, 1994.

Al-Attas. Aims and Objectives of Islamic Education, ed. S.M.N. al-Attas. London:/ Jeddah: Hodder \& Stoughton/King Abdul Aziz University, 1979.

Al-Attas, A Commentary on the Hujjat al-Shiddiq of Nur al-Din al-Raniri. Kuala Lumpur: Ministry of Culture Malaysia, 1986.

Al-Attas, Islam \& Filsafat Sains. Bandung: Mizan, 1995.

Al-Attas, Islam and Secularism. Kuala Lumpur: Angkatan Belia Islam Malaysia, 1978.; cet. kedua dengan pengantar baru oleh ISTAC, 1993.

Al-Attas,ISLAM: The Concept of Religion and The Foundation of Ethics and Morality. Malaysia: ABIM, 1976.

Al-Attas, Risalah Untuk Kaum Muslimin. Kuala Lumpur: ISTAC, 2001. 
Al-Attas, The Intuition of Existence: A Fundamental Basis of Islamic Metahpysics. (Kuala Lumpur: International Institute of Islamic Thought and Civilization International Islamic University, 1990.

Al-Ghazali, Al-Maqșad Al-Asnā fı̀ Syarh Asmā’ Allāh al-Husnā. Terjemahan dan catatan oleh David Burrel dan Nazih Daher. The Ninety-Nine Beautiful Names of God. Cambridge: Islamic Texts Society, 1992.

Al-Ghazali, Ihyyā' 'Ulūm al-Dīn, juz. I\& IV. Damaskus: Dār Al-Fikr, 1427 H/20o6 M. Al-Ghazali, Minhāj al-'̄̄bidīn. Surabaya: Maktabah Mahkota, tth.

Al-Ghazali, Mukāshafat al-Qulūb. Singapura-Jeddah-Indonesia: Al-Haramain, tth.

Al-Qardhawi, Yusuf, Al-Hayāh al-Rabbāniyyah wa al-Ilm. Kairo: Maktabah Wahbah, $1416 \mathrm{H} / 1995 \mathrm{M}$.

Armas,Adnin, "Menelusuri Jejak Sekularisasi”, dalam Hamid Fahmi Zarkasyi dkk., Tantangan Sekularisasi dan Liberalisasi di Dunia Islam. Jakarta Selatan: Khairul Bayan, 2004.

Beg,Muhammad Abdul Jabbar,The Muslim World League Journal, edisi November-Desember, 1983 .

C.E. Bosworth, E. Van Donzel, B. Lewis, Charles Pellat, eds., Encyclopaedia of Islam, edisi baru. Leiden: E.J. Brill, 1986.

Cox,Harvey, "Why Christianity Must Be Secularized" in The Great Ideas Today 1967. Chicago: Encyclopaedia Britannica, Inc, 1967.

Dzulhadi, Qosim Nursheha, Jejak Sophisme dalam Liberalisasi Pemikiran di Indonesia, makalah disampaikan dalam bedah buku: Membongkar Kedok Liberalisasi di Indonesia, InPAS Surabaya, di Masjid Nuruzzaman Unair, 16 Februari 2013.

Feurbach,Ludwig,The Essence of Christianity, penerjemah George Eliot. New York: Prometheus Books, 1989.

Gassett,Jose Ortega Y.,The Mission of the University. Disunting dan diterjemahkan oleh Howard Lee Nostrand. New York: W.W. Norton, 1994.

Grunebaum,Gustave von,Medieval Islam: A Vital Study of Islam at its Zenith, edisi ke-2. Chicago: Phoenix Books/Univ. of Chicago Press, 1962.

Ibnu Khaldun, Muqaddimah Ibn Khaldun. Dar al-Kutub Al-'Ilmiyyah, 2006. 
Jaeger,Werner,Paideia: The Ideals of Greek Culture, 3 jil. Diterjemahkan oleh Gilbert Highet, edisi ke-2. New York/Oxford: Oxford University Press, 1945. Jarrett,James L.,Educational Philosophy of the Sophists. New York: Teachers College-Columbia University Press, 1965 .

Jr.J.H. Randall,The Making of the Modern Mind, edisi ulang tahun ke-5o. Kata pendahuluan oleh Jacques Barzun. New York: Columbia University Press, 1976.

Lamont,Corliss, The Philosophy of Humanism, cetakan ulang edisi 1949. New York: The Wisdom Library, 1957.

Livingstone,E.A.,Oxford Concise Dictionary of Christian Church. Oxford: Oxford University Press, 1996.

Lomas, Robert The Invisible College. London: Headline Book Publishing, 2002. Majalan Pemikiran dan Peradaban Islam, "Pengantar: Ilmu Asas Pencerahan Peradaban", ISLAMIA, Thn I, No 6, Juli-September 2005.

Maritain,Jacques,Education at the Crossroads. New Haven dan London: Yale University Press, 1943.

Most,Father William G., Catholic Apologetics Today. Rockford: Tan Books and Publisher Inc., 1986.

Nasr,Seyyed Hossein,Science and Civilization in Islam. Cambgridge, Massachusetts: Harvard University Press, 1968.

Newman, John Henry,The Idea of a University Difined and Illustrated, edisi 1873. London: Routledge \& Thoemmes Press, 1994.

Nursi, Beiduzzaman Sa'id, Al-Maktūbat, terj. Ihsan Kasim Salih. Al-Qahirah: Syirkah Sozler li an-Nasyr, 2004.

Nursi, Beiduzzaman Sa'id, Al-Lama'āt, terj. Ihsan Kasim Salih. Al-Qahirah: Syirkah Sozler li an-Nasyr, 2004.

Nursi, Beiduzzaman Sa'id, Anwār al-Haqüqah: Mabāḥith fı́ al-Taṣawwuf wa alSulūk, terj. Ihsan Kasim Salih. Al-Qahirah: Syirkah Sozler li an-Nasyr, 2006. Perry, Marvin, Western Civilization. Boston: Houghton Mifflin Company, 1997. Rosenthal,Franz,Knowledge Triumphant: The Concept of Knowledge in Medieval Islam. Leiden: E.J. Brill, 1970. 
Smart,Ninian, Worldview, Crosscultural Explorations of Human Belief, Charles Sribner's sons, New York, n.d.

Tibawi,Abdul Latif, "Philosophy of Muslim Education”, Islamic Quarterly, Jil. 10, No. 2, Juli 1957.

Thinking About Philosophical Problem, Wadsworth, Thomson Learning, United States.

Wall,Thomas F.,Thinking Critically About Philosophical Problem, A Modern Introduction, Wadsworth, Thomson Learning, Australia, 2001.

Wan Daud, The Educational Philosophy and Practice of Syed Muhammad Naquib Al-Attas. Kuala Lumpur: ISTAC, 1998.

Wan Daud, Rihlah Ilmiah Wan Mohd Nor Wan Daud: Dari Neomodernisme ke Islamisasi Ilmu Pengetahuan Kontemporer. Malaysia-Indonesia: UTM-CASIS \& INSISTS, 2012.

Zarkasyi, Hamid Fahmy, Misykat: Refleksi tentang Islam, Westernisasi \& Liberalisasi. Jakarta: INSISTS, 2012.

Zarkasyi, Hamid Fahmy, Pandangan Hidup, Ilmu Pengetahuan dan Pendidikan Islam, makalah disampaikan pada workshop Ilmu Pengetahuan dan Pendidikan di Sekolah Tinggi Lukman ul Hakim, Hidayatullah Surabaya, 12-13 Agustus 2005 .

Zarkasyi,Hamid Fahmy,Membangun Peradaban Islam Yang Bermartabat . Gontor, CIOS, 2009.

Gibs \& Kramers, Shorter Encyclopedia of Islam. Leiden: E.J. Brill, 1965.

Muhammad Yusuf Musa, Falsafah al-Akhlāqfíal-Islām, cet. 3. Kairo: Muassasat al-Khaniji, 1963 .

Abd. Al-Hamid Yunus, Dā'irat al-Ma'ārif al-Islāmiyyah, juz III. Kairo: Dār alShab, tt.

Abd. Qadir Mahmud, Al-Falsafah al-Ṣūfuyyah fì al-Islām. Dār al-Fikr al-'Arabī, tt.. Abd. Al-Karim Ibn Ibrahim al-Jili, al-Insān al-Kāmil fı̀ Ma'rifat al-Awākhir wa al-Awāil. Dār al-Fikr, tt. 